\title{
Sexual maturation in captive spiny lobsters, Jasus edwardsii, and the relationship of fecundity and larval quality with maternal size
}

Greg G. Smith and Arthur J. Ritar*

Marine Research Laboratories, Tasmanian Aquaculture and Fisheries Institute, University of Tasmania, Nubeena Crescent, Taroona, Tasmania 7053, Australia

(*Corresponding author: Tel: +61 (3) 62277 294; Fax: +61 (3) 62278 035;

e-mail: Arthur.Ritar@utas.edu.au)

\section{Summary}

Reproductive and somatic parameters of southern rock lobsters, Jasus edwardsii, held captive since puerulus and wild-caught adults were examined in terms of size at onset of maturity (SOM) and fecundity, culminating in an examination of how adult size may relate to larval competency. The SOM was much smaller in captive animals (62.5 mm carapace length, CL) compared to historical fishery data and indicated that precocious maturation may be induced in captivity. During this study, the fecundity was assessed as the number of viable phyllosoma at hatch, which was $\sim 45 \%$ of egg estimates from the historical fishery data, suggesting either declining egg numbers in wild stocks over time or that major egg loss occurs during embryonic development. The association between SOM and sexual dimorphism was examined for several morphometric parameters. In females, the SOM was concomitant with increases to the width of the $1^{\text {st }}$ and $2^{\text {nd }}$ abdominal segments above $62.5 \mathrm{~mm}$ CL, while $2^{\text {nd }}$ and $3^{\text {rd }}$ leg length increased disproportionately in males compared to females above $77.5 \mathrm{~mm}$ CL. There were significant correlations between viable fecundity and female size $(r=0.92)$, phyllosoma size $(r=0.74)$ and larval viability as quantified by stress indices $(r=-0.56)$ and LD-50 $(r=0.56)$, indicating that larger females produce larger, more viable larvae. These physiological traits in larval, juvenile and adult animals may have an impact on fishery and aquaculture production.

Keywords: fecundity, Jasus edwardsii, larval quality, morphometrics, sexual maturation.

\section{Introduction}

The spiny lobster Jasus edwardsii is endemic to southern Australia and New Zealand and it sustains an important fishery in Tasmania, currently with an annual catch of 1500 tonnes (Gardner et al., 2002). A major determinant of the sustainability of spiny lobster fisheries is their lifetime egg production $(\mathrm{E} / \mathrm{R})$ and comprises factors that include size at onset of maturity (SOM) and size-specific reproductive output (fecundity) (Wenner, 1974; MacDiarmid, 1989; Pollock, 1991, 1997).

SOM can vary considerably in spiny lobsters; it is often locality-specific and controlled by phenotypic expression (Pollock, 1997). The SOM of a population is defined as the size when at least $50 \%$ of animals in a $5 \mathrm{~mm}$ CL size class are mature (George and Morgan, 1979). Some influences on SOM may include environmental, biological or social factors involving specific interactions between temperature, food, shelter, growth rate, age, metabolic rate and population density (Annala et al., 1980; Pollock, 1993) with larger SOM resulting in larger E/R (Pollock, 1993).

Sexual maturity in J. edwardsii females can be assessed by noting the presence of eggs attached to pleopods, or in the absence of eggs, well-developed ovigerous setae (Annala et al., 1980; MacDiarmid, 1989). The onset of sexual maturity in spiny lobsters has a number of morphometric ramifications, which were first noted by Kubo (1938) investigating claims that two spiny lobster variants occupied the same habitat in Japanese waters. The 
study revealed that animals considered as similar but separate species were in fact the two sexes of the same species, Panulirus japonicus. A distinguishing trait recognized by Kubo (1938) was the allometric elongation of male legs and hence sexual dimorphism based on the relationship between leg length and sex. Since then, the relationship between the morphology of male and female spiny lobsters and SOM have been studied in several species and now incorporate female tail characteristics (Gordon, 1960; Berry, 1971). The generalized pattern in spiny lobsters is for females to have broader tails than males to facilitate egg carrying, while males develop a larger carapace and legs, which play a role in courtship and mating (Frusher et al., 1999).

Fecundity in crustaceans is generally expressed in terms of egg number and is based on relationships with carapace length (CL) (Herrick, 1895). Hence, the maximum number of eggs is constrained by body size (MacDiarmid, 1989). While increasing E/R may be advantageous to larval production in wild populations, large SOM in culture means that energy reserves are partitioned to somatic rather than gonadal growth.

Egg loss in wild $J$. edwardsii is generally considered to be low in Australian waters (Morgan, 1972; Kennedy, 1993 unpublished Tasmanian fishery data) although there are reports of significant losses in many other crustacean species (Perkins, 1971; Annala and Bycroft, 1987; Waddy and Aiken, 1991; Tuck et al., 2000). From an aquaculture perspective, it is not known whether viable fecundity i.e., the number of newly-hatched phyllosoma produced by a female, is lower than egg production derived from fishery estimates particularly as captive animals are subject to additional husbandry stresses during the incubation period. Thus, there may be a need to review broodstock husbandry procedures if they reduce viable fecundity and adversely affect larval viability.

This study examined the SOM in captive lobsters, subsequent changes to allometry in males and females, the relationship between viable fecundity and historical data on egg numbers, and the association of viable fecundity and larval quality with maternal size.

\section{Materials and Methods}

\section{Broodstock collection and holding}

Experimental work was carried out at the Tasmanian Aquaculture and Fisheries Institute, Marine Research Laboratories (TAFI, MRL), Hobart, Australia. A total of 238 juvenile and adult $J$. edwardsii (116 males, 122 females) involved in the study were sourced from Flinders Island ( $\left.40^{\circ} 32^{\prime} \mathrm{S}, 148^{\circ} 16^{\prime} \mathrm{E}\right)$, the Bicheno region ( $41^{\circ} 51^{\prime} \mathrm{S}, 148^{\circ}$ $\left.21^{\prime} \mathrm{E}\right)$ and Crayfish Point ( $\left.42^{\circ} 56^{\prime} \mathrm{S}, 147^{\circ} 20^{\prime} \mathrm{E}\right)$. The distribution of gender and CL from the different sources were: Flinders Island, 21 males $(105.5-116.0 \mathrm{~mm})$ and 39 females (101.6-154.0 mm); Crayfish Point, 25 males (132.2-170.0 mm); adult captive stock from Bicheno, 8 males (115.0-127.2 mm) and 27 females (106.6-151.1 mm); and animals held captive from pueruli collected two years earlier from Bicheno, 62 males (29.9-93.3 mm) and 56 females (30.0-87.2 mm). Animals collected from Bicheno as pueruli were held for two years to determine SOM in captivity. Analysis of covariance determined there was no significant difference between the relationship of CL and morphometrics (total length, abdominal segment length and width, and leg length) attributed to source. Therefore, source data were pooled for the comparison of male and female morphometrics.

Post-capture, all lobsters were held in $4000 \mathrm{~L}$ square fibreglass tanks, with adults at a density of 30-40 $\operatorname{tank}^{-1}$ while pueruli/juveniles were held at 150-200 tank ${ }^{-1}$. Tanks were supplied with flow-through seawater at $600 \mathrm{~h}^{-1}$ under conditions of ambient temperature (seasonal range $9.5-18.5^{\circ} \mathrm{C}$ ) and photoperiod (seasonal range 8.5-15.3 h daylight at $<4$ $\mu \mathrm{mol} \mathrm{s} \mathrm{m}^{-1}$ ). Tanks contained concrete blocks arranged to provide numerous shelters for 
lobsters. Animals were fed a diet of mussels (Mytilus edulis), squid (Nototodarus sloanii) and penaeid pellets (Vital prawn, Higashimaru-Japan) 3 times week $^{-1}$ to satiation.

\section{Size at onset of maturity}

SOM was assessed as the midpoint of the smallest $5 \mathrm{~mm}$ CL size class where at least $50 \%$ of animals were sexually mature (Annala et al., 1980; MacDiarmid, 1989). As sampling was conducted during the latter part of the egg-bearing season (August, midwinter), animals were considered mature if they were bearing external eggs (Annala et al., 1980). The monitoring of ovigerous setae on the endopodites of the pleopods (Kensler, 1967; Annala et al., 1980; MacDiarmid, 1989; Groeneveld and Melville-Smith, 1994) was deemed unnecessary with none present on non-ovigerous animals $<60 \mathrm{~mm}$ CL, while 90$100 \%$ of animals $>60 \mathrm{~mm}$ CL were ovigerous.

\section{Broodstock morphological measures}

Male (M) and female (F) animals utilized for the morphometric study ranged in size from 29.9-170.0 mm CL for males and 30.0-154.0 mm CL for females, with CL measured from the base of the antennal platform to the dorsal posterior margin of the carapace along the dorsal midline. Other morphological measures included:

- Total length (M, 74.0-415.0 mm; F, 73.5-404.0 mm) - the distance from the base of the antennal platform to the tip of the telson measured along the dorsal midline.

- Wet weight (ww) (M, 11.5-2,222.0 g; F, 13.0-1,766.0 g) - body weight of the animal (after larval hatch in females) when removed from the water for $30 \mathrm{~s}$ to allow the draining of excess water.

- $1^{\text {st }}$ abdominal segment length (M, 7.2-42.2 mm; F, 8.3-39.4 mm) and $2^{\text {nd }}$ abdominal segment length (M, 7.2-43.3 mm; F, 8.3-41.0 mm) - the longitudinal distance between the extremities of the segment cuticle measured along the dorsal midline.

- $1^{\text {st }}$ abdominal segment width (M, 15.0-84.0 mm; F, 16.1-97.2 mm) and $2^{\text {nd }}$ abdominal segment width (M, 14.4-83.8 mm; F, 16.1-99.0 mm) - the maximum distance between the pleural spurs.

- $2^{\text {nd }}$ leg length (M, 34.0-255.0 mm; F, 35.0-199.0 mm) and $3^{\text {rd }}$ leg length $(\mathrm{M}, 36.0-283.0$ $\mathrm{mm}$; F, 40.0-220.0 mm) - the distance measured along the ventral midline of the leg from the proximal margin of the ischium to the dactyl tip.

\section{Collection and counting of viable phyllosoma}

Viable fecundity was the total number of phyllosoma produced by each female and did not include egg loss, infertile or non-viable eggs or larvae failing to progress beyond naupliosoma. Naupliosoma are a brief non-feeding post-hatch stage typically lasting $0.5-1$ $\mathrm{h}$ before the moult to Stage I phyllosoma (Tong et al., 2000). Proximity to hatch was determined by change in egg colour (from red at egg extrusion becoming orange and finally translucent brown at hatch) and monitoring of egg eye indices (Tong et al., 2000). About one week prior to hatch, ovigerous females were isolated into individual $20 \mathrm{~L}$ hatching containers (Smith et al., 2003a). Larvae hatched synchronously at dawn on each of 4-7 consecutive days (Smith et al., 2002), were transferred to $10 \mathrm{~L}$ of aerated $18^{\circ} \mathrm{C}$ seawater and the number estimated from triplicate $75 \mathrm{ml}$ subsamples. Cumulative totals of phyllosoma for each female were tallied over the duration of the hatch-out period.

\section{Phyllosoma viability and morphological measures}

Newly-hatched phyllosoma were subjected to a number of treatments, including: 
- Lethal Dose 50 (LD-50), the time (d) for 50\% of unfed Stage I larvae to die. This is a measure of endogenous reserves and physiological condition. Larvae $\left(100 \mathrm{~L}^{-1}\right)$ were cultured in triplicate $1 \mathrm{~L}$ glass beakers containing lightly aerated seawater $\left(35 \%, 18^{\circ} \mathrm{C}\right.$ ) and antibiotics (oxytetracycline hydrochloride 25ppm, Intervet Engemycin 100, Australia). Water was exchanged and larvae counted daily. Treatments were terminated on the attainment of an average $50 \%$ mortality across replicates.

- A $1 \mathrm{~h}$ temperature/salinity activity test (Smith et al., 2003b). Briefly, triplicate $250 \mathrm{ml}$ plastic sample jars containing 20 larvae were exposed to stressors of warm water $\left(21^{\circ} \mathrm{C}\right)$ and low salinity (10\%o). Survival was monitored at 3 min intervals, with a cumulative stress index compiled at the completion of $1 \mathrm{~h}$ exposure. Low indices were indicative of better survival in culture.

- Measures of egg and phyllosoma size. A total of 20 eggs and phyllosoma were measured on the first day that phyllosoma hatched from the females. Cross-sectional diameters of eggs and total lengths of phyllosoma (anterior tip of the cephalothorax to the posterior point of the abdomen) were measured to the nearest $0.05 \mathrm{~mm}$ using an overhead projection microscope (Nikon Profile Projector, model 6C, 20 times magnification).

\section{Statistics}

Statistical analyses were conducted using one-way analysis of variance (ANOVA) with Tukey-Kramer HSD tests used for post-hoc comparison (Sokal and Rohlf, 1995). Log transforms were performed on non-homogeneous data. In the analysis of sexual dimorphism, the point of differentiation was determined by dividing the parameter (leg length, carapace length or width) into $5 \mathrm{~mm}$ CL size classes (i.e., 55-59.9 mm, 60-64.9 $\mathrm{mm}$, etc.) for comparison. When consecutive size classes demonstrated sexual dimorphism, the midpoint of the smallest class was nominated as the point of deviation. Probabilities of $<0.05$ were considered significantly different unless stated otherwise. Data are presented as mean \pm sem. Statistics were executed using JMP version 5 (SAS Institute Inc., Cary, NC, USA.).

\section{Results}

\section{Juvenile and adult morphometrics}

Analysis of lobster morphometrics revealed the interaction between CL and ww which was best described by the power equation $y=a * C L$ ', where ' $a$ ' and ' $b$ ' were constants, with lobster ww increasing at a greater rate than CL, but the relationship being similar for both sexes (Fig. 1a). Linear relationships also existed between CL and total length (Fig. $1 b)$ but differing significantly between sexes $\left(\mathrm{F}_{1,232}=84.31, \mathrm{P}<0.0001\right)$. CL was proportionally longer in males than females when compared to total length.

Regression analysis of CL and the $1^{\text {st }}$ abdominal segment length demonstrated significant differences between males and females $\left(F_{1,232}=18.06, P<0.0001\right.$, Fig. 2a) with females having longer abdominal segments than males. Similar results were obtained for the $2^{\text {nd }}$ abdominal segment length $\left(\mathrm{F}_{1,232}=24.90, \mathrm{P}<0.0001\right.$, Fig. $\left.2 \mathrm{~b}\right)$. However, analysis of the $5 \mathrm{~mm}$ CL size classes could not discern the point where the length of the abdominal segment deviated (ANOVA).

The slopes of the regressions between CL and $1^{\text {st }}$ abdominal segment width differed significantly between sexes $\left(\mathrm{F}_{1,232}=503.47, P<0.0001\right.$, Fig. 3a), and became discernibly wider in females in the 60-64.9 mm CL group and larger (ANOVA), i.e. midpoint $62.5 \mathrm{~mm}$ CL. Differences between the sexes were greater for the width of the $2^{\text {nd }}$ abdominal segment 
$\left(F_{1,232}=624.74, P<0.0001\right.$, Fig. $\left.3 b\right)$, but the point of differentiation was the same at the 60$64.9 \mathrm{~mm}$ CL group (ANOVA), i.e. midpoint $62.5 \mathrm{~mm}$ CL.

There were strong linear relationships between CL and $2^{\text {nd }}$ walking leg length, with different slopes evident between the sexes $\left(F_{1,232}=311.63, P<0.0001\right.$, Fig. $\left.4 \mathrm{a}\right)$. Males exhibited longer legs than females and the point of differentiation was the 75-79.5 mm CL group (ANOVA), i.e. midpoint $77.5 \mathrm{~mm}$ CL. Differentiation between the sexes was improved using length measures of the $3^{\text {rd }}$ walking leg $\left(F_{1,232}=372.40, P<0.0001\right.$, Fig. $\left.4 \mathrm{~b}\right)$, but the point of differentiation was the same as the 75-79.5 mm CL group (ANOVA), i.e. midpoint $77.5 \mathrm{~mm}$ CL.

Hatch, viable fecundity and phyllosoma quality assessments

Of the 122 ovigerous females, the smallest had a CL of $58 \mathrm{~mm}$, with the remaining 5 animals in this size class (55-59.9 mm) not ovigerous. The next size class (60-64.9 mm CL) contained 4 animals, all ovigerous, while subsequent $5 \mathrm{~mm}$ CL classes contained 90$100 \%$ ovigerous females. The SOM was therefore determined to be $62.5 \mathrm{~mm}$ CL and all these animals were captured from Bicheno as pueruli and held at TAFI MRL.

Thirty ovigerous females were chosen randomly from across the CL size range to assess viable fecundity and of these, 24 were used for assessment of phyllosoma quality (egg diameter, phyllosoma size and LD-50). The size of animals sampled for viable fecundity varied from 58-152 mm CL, with ww ranging from 110-2,025 g and viable phyllosoma numbers ranging from $10,500-300,000$. Viable fecundity in this range was described by the power equation $\mathrm{y}=0.1028 * \mathrm{CL}^{2.9204}\left(\mathrm{R}^{2}=0.9331, P<0.0001\right)$ (Fig. 5).

Minimum and maximum egg diameter, phyllosoma size and LD-50 were $0.70-0.83 \mathrm{~mm}$, 1.88-2.08 mm and 8-19 d, respectively. There were significant correlations between viable fecundity and CL $(r=0.92)$ and phyllosoma size $(r=0.74)$ with reduced correlates for egg size $(r=0.55)$, stress indices $(r=-0.56)$ and survival in LD-50 $(r=0.56)$. There was a low but significant correlation between the LD-50 and phyllosoma size $(r=0.49)$. Phyllosoma stress indices demonstrated a strong correlation with survival in the LD-50 $(r=-0.89)$ and reduced correlates to egg size $(r=-0.46)$ and phyllosoma size $(r=-0.53)$. CL was correlated with egg size $(r=0.53)$ and phyllosoma size $(r=0.70)$.

\section{Discussion}

The original study of $J$. edwardsii wild stocks in Tasmania by Hickman (1945) found that the smallest ovigerous female had a SOM of $74 \mathrm{~mm}$ CL. Since then, the use of SOM based on 50\% maturity within a CL size class has been a regular feature of fisheries monitoring (Gardner et al., 2002). In Tasmanian waters, there is a positive relationship between SOM and temperature, with larger SOM occurring in warm northern waters compared to cooler southern regions (Gardner et al., 2005). In the present study, the SOM for captive animals sourced from the Bicheno region as pueruli and held captive for two years was much lower ( $62.5 \mathrm{~mm} \mathrm{CL}$ ) than observed historically for adults from either Bicheno (93.2 mm CL) or Crayfish Point Reserve (83.4 mm CL) (Gardner et al., 2002), which was also our water source providing ambient temperature conditions. This indicates that temperature is not solely responsible for determining SOM in J. edwardsii. In fact, SOM in the New Zealand fishery is inversely related to water temperature (Annala et al., 1980), while no relationship is apparent in some other lobster fisheries (Kuhlmann and Walker II, 1999).

There have been reductions to SOM in heavily exploited wild fisheries, especially with removal of large mature animals (Warner et al., 1977; Polovina, 1989). It may be that due to heavy exploitation, smaller females mature early and are recruited to maintain egg 
production in the population (Polovina, 1989; Chubb, 1994; Pollock, 1997). A similar mechanism may be present in captive stock where large mature individuals are absent. We note that across a wide range of environments and crustacean species, SOM is a malleable parameter but there is little knowledge of the cues that initiate maturity. If the aquaculture potential of $J$. edwardsii is to be realized, conditions to encourage allocation of resources to somatic growth, rather than to reproduction, need to be identified.

There was a high degree of synchronicity in the onset of maturity in captive J. edwardsii animals with the number of mature females within a size cohort increasing in consecutive size classes from $17 \%$ at $55-59.9 \mathrm{~mm}$ CL to $100 \%$ at $60-64.9 \mathrm{~mm}$ CL. The typical pattern for SOM in wild stocks is for 3-5 consecutive cohorts to contain increasing proportions of ovigerous females before $50 \%$ of a size class is regarded as mature (Annala et al., 1980; MacDiarmid, 1989; Gardner et al., 2002). However, this pattern is not universal, with attainment of maturity within consecutive size classes previously noted in wild lobsters with small SOM (60-75 mm CL) (Annala et al., 1980), and similar to our study.

Small changes to the CL of juveniles and adults resulted in large increases in weight in males and females, which also occurs in other spiny lobsters (Berry, 1971). In animals of similar total length, males have a larger CL, and considering the relationship between CL and weight, they will also be heavier than females. The greater length and width of the female abdominal segments is a trait associated with egg bearing and the formation of an egg chamber (Berry, 1971; Frusher, 1999). In this study, the change in tail shape appears to be closely related to the estimated SOM of $62.5 \mathrm{~mm}$ CL, and is confirmed by the divergence of male and female tail widths at this size. The point of dimorphism between the sexes may provide a useful method to determine the SOM for females. The use of morphometrics has been predominately confined to the differentiation of male sexual characteristics (Kubo, 1938; Juinio, 1987). In spiny lobsters, this has been associated with allometric elongation of the $3^{\text {rd }}$ walking leg (Kubo, 1938; Gordon, 1960; Berry, 1971; George and Morgan 1979; Juinio, 1987; Plaut 1993) providing males with an increased capacity to participate in courtship and mating rituals (Kubo, 1938; MacDiarmid, 1989; Berry, 1971). This was also evident during our study where dimorphism between the sexes was evident at $77.5 \mathrm{~mm}$ CL, within the range previously reported for SOM in male $J$. edwardsii (65-85 mm CL) (Fielder, 1964; MacDiarmid, 1989).

The relationship between large females producing large phyllosoma from large eggs (Annala, 1991) was confirmed, as was the potential for larger larvae to result in better survival (MacDiarmid and Kittaka, 2000; Smith et al., 2003b). The relationship between broodstock and larval size is an important finding, and provides an additional tool for selecting competent larvae for culture. During larval culture over successive stages, larger newly-hatched larvae become larger Stage II larvae, and so on. This is a typical growth pattern for crustaceans (Kunish and Anger, 1984; Lovrich and Vinuesa, 1995), where body size at ecdysis is proportional to the size of their previous exoskeleton. This is a factor especially important when selecting lobster larvae for culture, where the larval phase encompasses numerous instars and takes in excess of 300 days to complete (Kittaka, 1994). It may also be significant for the fishery in that larger females produce larger, more competent larvae that are more likely to develop to pueruli.

Two measures of phyllosoma competency at hatch were used: activity test and LD-50. The activity test was virtually instantaneous $(1 \mathrm{~h})$ and more effective than the LD-50 in predicting larval performance during long-term culture, which agrees with our previous study (Smith et al., 2003b). Although LD-50 provides an indication of larval competency, the extended duration required to obtain results allows external factors, perhaps including bacterial contamination, to reduce the predictive accuracy of the results. 
Although the slope of the viable fecundity curve for captive stocks was similar to most recent Tasmanian egg production estimates, with an equation $\mathrm{y}=0.1814 * \mathrm{CL}^{2.969}$ (Kennedy, 1993; unpublished Tasmanian fisheries data), the elevation was only 45\%, and much less than an earlier fecundity estimate by Hickman (1945). It is unclear if this is a real difference in fecundity or a discrepancy due to different sample size, geographic location or counting methodology. Parallels can be found in historic New Zealand fecundity records for $J$. edwardsii (Bradstock, 1950), which show lower values reported in recent times (MacDiarmid, 1989) giving the appearance that SOM is in a state of flux.

The lower phyllosoma number than the historic data on egg production appears to contradict the suggestion that minimal egg loss occurs during incubation (Kennedy, 1993; unpublished Tasmanian fisheries data). Possible explanations for lower phyllosoma numbers include seasonal differences in egg number due to environmental or nutritional factors (Kontara et al., 1997; Sampedro et al., 1997) or egg loss during incubation. Viable fecundity (i.e., the number of phyllosoma) may be influenced by sperm limitation at mating, egg loss during incubation, or the failure of newly-hatched larvae to progress beyond the naupliosoma stage. MacDiarmid and Butler (1999) found that a consequence of sperm limitation, where insufficient sperm are deposited at mating, was that unfertilized eggs did not attach securely after extrusion and were lost soon afterwards. Many hatch events contain a small proportion of naupliosoma where development stalls, which may account for about $10 \%$ of larvae and be more prominent on the first or last day of hatch (Smith et al., 2003a). However, any large discrepancy in viable fecundity must be assigned to egg loss/mortality. Up to $20 \%$ of eggs may be lost during incubation in wild $J$. edwardsii (Annala and Bycroft, 1987), while total egg loss may occur in captivity (MacDiarmid and Kittaka, 2000).

If egg loss was the cause of the lower than expected phyllosoma number, it is interesting that it was large and occurred systematically across all sizes. Stress during captivity can trigger over-grooming resulting in physical loss of eggs (A. MacDiarmid, personal communication) as well as under-grooming causing losses associated with fouling (Leucothrix mucor), fungus (Lagenidium) or parasitic infestations (e.g., the nemertean, Pseudocarcinonemertes homari) (Silberbauer, 1971; Shields and Kuris, 1989; Kuris, 1991). While it is acknowledged that stress may be significant in some captive systems, it is unlikely to reduce egg numbers in a consistent manner. It is more probable that a broadscale environmental or physiological parameter is responsible.

\section{Conclusion}

Factors affecting SOM are still largely undetermined in spiny lobsters, although there are benefits for the wild fishery and aquaculture in having large females produce large, viable phyllosoma. There were clear allometric relationships in both male and female $J$. edwardsii associated with SOM, which in the female provides potential correlates for use in assessing maturity in the absence of eggs or ovigerous setae. This study emphasized the differences recorded for fecundity as measured by egg production versus viable phyllosoma at hatch, respectively. Viable fecundity in captive animals was below expected fecundity derived from wild fisheries estimates, but whether this was due to normal phenomena of egg loss before hatch or was induced by captivity is an issue worthy of dedicated comparative studies.

\section{Acknowledgments}


We gratefully acknowledge the assistance of Mr. Ross Parker and Mr. Julian Harrington for the collection of lobsters, Drs. S. Frusher and C. Gardner from the Crustacean Assessment Section of TAFI MRL for the provision of wild fisheries data and Dr. Danielle Johnston for critical review of the manuscript.

\section{References}

Annala, J.H., McKoy, J.L., Booth, J.D. and Pike, R.B., Size at the onset of sexual maturity in female Jasus edwardsii (Decapoda: Palinuridae) in New Zealand. N.Z. J. Mar. Freshwat. Res., 14 (1980) 217-227.

Annala, J.H. and Bycroft, B.L., Fecundity of the New Zealand red rock lobster Jasus edwardsii. N.Z. J. Mar. Freshwat. Res., 21 (1987) 591-597.

Annala. J.H., Factors influencing fecundity and population egg production of Jasus species. In: Wenner, A. and Kuris, A. (eds.), Crustacean Issues. Vol. 7. Crustacean Egg Production. A.A. Balkema, Rotterdam, 1991, pp. 301-315.

Berry, P.F., The biology of the spiny lobster Panulirus homarus (Linnaeus) off the east coast of Southern Africa, Report 28. Oceanographic Research Institute, Durban, 75p. 1971.

Bradstock, C.A., A study of the marine spiny crayfish Jasus lalandii (Milne-Edwards), including accounts of autotomy and autospasy. Zoology Publs Vict. Univ. Coll. 7, 38 pp., 1950.

Chubb, C.F., Reproductive biology: issues for management. In: Phillips, B.F., Cobb, S.J. and Kittaka, J. (eds.), Spiny Lobster Management. Blackwell Scientific Publications, Cambridge, Great Britain, 1994, pp. 181-212.

Fielder, D.R., The spiny lobster, Jasus lalandii (H. Milne-Edwards), in South Australia. II. Reproduction. Aust. J. Mar. Freshwat. Res., 15 (1964) 133-144.

Frusher, S., Prescott, J. and Edmunds, M., Southern rock lobsters. In: Andrew, N. (ed.), Under Southern Seas - The Ecology of Australia's Rocky Reefs. University of NSW, Sydney, Australia, 1999, pp. 106-113.

Gardner, C., Frusher, S., Eaton, L. and Haddon, M., Fishery assessment report, Tasmanian rock lobster fishery 2000/2001. Marine Research Laboratories - Tasmanian Aquaculture and Fisheries Institute, University of Tasmania. Hobart, Australia. 117p. 2002.

Gardner, C., Hirst, A. and Haddon, M. Fishery assessment report, Tasmanian rock lobster fishery 2003/2004. Marine Research Laboratories - Tasmanian Aquaculture and Fisheries Institute, University of Tasmania. Hobart, Australia. 87p. 2005

George, R.W. and Morgan, G.R., Linear growth stages in the rock lobster (Panulirus versicolor) as a method of determining size at first physical maturity. Rapp. P.-V. Réun. Cons. Int. Explor. Mer (ICES), 175 (1979) 182-185.

Gordon, I., On the genus Justitia holthuis (Decapoda, Palinuridae), with a note on allometric growth in Panulirus ornatus (Fabricius). Crustaceana, 1 (1960) 295-306.

Groeneveld, J.C. and Melville-Smith, R., Size at onset of sexual maturity in the south coast rock lobster Palinurus gilchristi (Decapoda: Palinuridae). S. Afr. J. mar. Sci., 14 (1994) 219-223.

Herrick, F.H., The American Lobster. Bull. U.S. Fish. Com., 15 (1895) 1-252.

Hickman, V.V., Notes on the Tasmanian marine crayfish, Jasus lalandii (Milne Edwards). Pap. Proc. Roy. Soc. Tasmania, (1945) 27-38.

Juinio, M.A.R., Some aspects of the reproduction of Panulirus penicillatus. Bull. Mar. Sci., 41 (1987) 242-252. 
Kensler, C.B., Fecundity in the marine spiny lobster Jasus verreauxi (H Milne Edwards) (Crustacea: Decapoda: Palinuridae). N.Z. J. Mar. Freshwat. Res., 1 (1967) 143-155.

Kittaka, J., Culture of phyllosomas of spiny lobster and its application to studies of larval recruitment and aquaculture. Crustaceana, 66 (1994) 258-270.

Kontara, I.K., Merchie, G., Lavens, P., Robles, R., Nelis, H., De Leenheer, A. and Sorgeloos, P., Improved production of postlarval white shrimp through supplementation of L-ascorbyl-2-polyphosphate in their diet. Aquacult. Int., 5 (1997) 127-136.

Kubo, I., Notes on the sexual dimorphism of the spiny lobster, Panulirus japonicus (v. Siebold). J. Imp. Fish. Inst., 33 (1938) 101-107.

Kuhlmann, M.L. and Walker II, R.E., Geographic variation in size structure and size at maturity in the crab Pilumnus sayi (Crustacea: Decapods: Xanthidae) in the northern Gulf of Mexico. Bull. Mar. Sci., 64 (1999) 535-541.

Kunisch, M. and Anger, K., Variation in development and growth rates of larval and juvenile spider crabs Hyas araneus reared in the laboratory. Mar. Ecol. Prog. Ser., 15 (1984) 293-301.

Kuris, A.M., A review of patterns and causes of crustacean brood mortality. In: Wenner, A. and Kuris, A. (eds.), Crustacean Egg Production. Crustacean Issues Vol. 7. A.A. Balkema, Rotterdam, 1991, pp. 117-141.

Lovrich, G.A. and Vinuesa, J.H., Growth of immature false southern king crab, Paralomis granulosa (Anomura, Lithodidae), in the Beagle Channel, Argentina. Scientia Marina, 59 (1995) 87-94.

MacDiarmid, A.B., Size at onset of maturity and size-dependent reproductive output of female and male spiny lobsters Jasus edwardsii (Hutton) (Decapoda, Palinuridae) in northern New Zealand. J. Exp. Mar. Biol. Ecol., 127 (1989) 229-243.

MacDiarmid, A.B. and Butler, M.J., Sperm economy and limitation in spiny lobsters. Behavioral Ecology and Sociobiology, 46 (1999) 14-24.

MacDiarmid, A.B. and Kittaka, J., Breeding. In: Phillips, B.F. and Kittaka, J. (eds.), Spiny Lobsters: Fisheries and Culture, 2nd Ed. Blackwell Scientific Publications, Oxford, 2000, pp. 485-507.

Morgan, G.R., Fecundity in the Western rock lobster Panulirus longipes cygnus (George) (Crustacea: Decapoda: Palinuridae). Aust. J. Mar. Freshwat. Res., 23 (1972) 133-141.

Perkins, H.C., Egg loss during incubation from offshore northern lobsters (Decapoda: Homaridae). Fish. Bull., 69 (1971) 451-453.

Plaut, I., Sexual maturity, reproductive season and fecundity of the spiny lobster Panulirus penicillatus from the Gulf of Eilat (Aqaba), Red Sea. Aust. J. Mar. Freshwat. Res., 44 (1993) 527-535.

Pollock, D.E., Population regulation and stock-recruitment relationships in some crayfish and lobster populations. In: Wenner, A. and Kuris, A. (eds.), Crustacean Egg Production. Crustacean Issues Vol. 7. A.A. Balkema, Rotterdam, 1991, pp. 247-266.

Pollock, D.E., Recruitment overfishing and resilience in spiny lobster populations. ICES J. Mar. Sci., 50 (1993) 9-14.

Pollock, D.E., Egg production and life-history strategies in some clawed and spiny lobster populations. Bull. Mar. Sci., 61 (1997) 97-109.

Polovina, J., Density dependence in spiny lobster, Palinurus marginatus, in the Northwestern Hawaiian Islands. Can. J. Fish. Aquat. Sci., 46 (1989) 660-665.

Sampedro, M.P., Fernandez, L., Freire, J. and Gonzalez-Gurriaran, E., Fecundity and reproductive output of Pisidia longicornis (Decapoda, Anomura) in the Ria de Arousa (Galicia, NW Spain). Crustaceana, 70 (1997) 95-110. 
Shields, J.D. and Kuris, A.M., Carcinonemertes wickhami n. sp. (Nemertea), a symbiotic egg predator from the spiny lobster Panulirus interruptus in southern California, with remarks on symbiont-host adaptations. Fish. Bull. U.S., 88 (1989) 279-287.

Silberbauer, B.I., The biology of the South African rock lobster Jasus lalandii (J. Milne Edwards) 1. Development. S. Afr. Div. Sea Fish. Invest Rep., 92 (1971) 1-70.

Smith, E.G., Ritar, A.J., Carter, C.G., Dunstan, G.A. and Brown, M.R., Morphological and biochemical characteristics of phyllosoma after photothermal manipulation of reproduction in broodstock of the spiny lobster, Jasus edwardsii. Aquaculture, 220 (2003a) 299-311.

Smith, G.G., Ritar, A.J., Thompson, P.A., Dunstan, G.A. and Brown, M.R., The effect of embryo incubation temperature on indicators of larval viability in Stage I phyllosoma of the spiny lobster, Jasus edwardsii. Aquaculture, 209 (2002) 157-167.

Smith, G.G., Ritar. A.J. and Dunstan, G.A., An activity test to evaluate larval competency in spiny lobsters (Jasus edwardsii) from wild and captive ovigerous broodstock held under different environmental conditions. Aquaculture, 218 (2003b) 293-307.

Sokal R.R. and Rohlf J.F., Biometry: The principles and practice of statistics in biological research. Freeman. New York, 1995.

Tong, L.J., Moss, G.A., Pickering, T.D. and Paewai, M.P.,Temperature effects on embryo and early larval development of the spiny lobster Jasus edwardsii, and description of a method to predict larval hatch times. Mar. Freshwater Res., 51 (2000) 243-248.

Tuck, I.D., Atkinson, R.J.A. and Chapman, C.J., Population biology of the Norway lobster, Nephrops norvegicus (L.) in the Firth of Clyde, Scotland II: fecundity and size at onset of sexual maturity. ICES J. Mar. Sci., 57 (2000) 1227-1239.

Waddy, S.L. and Aiken, D.E., Egg production in the American lobster, Homarus americanus. In: Wenner, A. and Kuris, A. (eds.), Crustacean Egg Production. Crustacean Issues Vol. 7. A.A. Balkema, Rotterdam, 1991, pp. 267-290.

Warner, R.E., Combs, C.L. and Gregory, D.R., Biological studies of the spiny lobster, Panulirus argus (Decapoda; Palinuridae), in south Florida. Proc. Gulf Carib. Fish. Inst., 29 (1977) 166-183.

Wenner, A.M., Fusaro, C. and Oaten, A., Size at onset of sexual maturity and growth rate in crustacean populations. Can. J. Zool., 52 (1974) 1095-1106. 

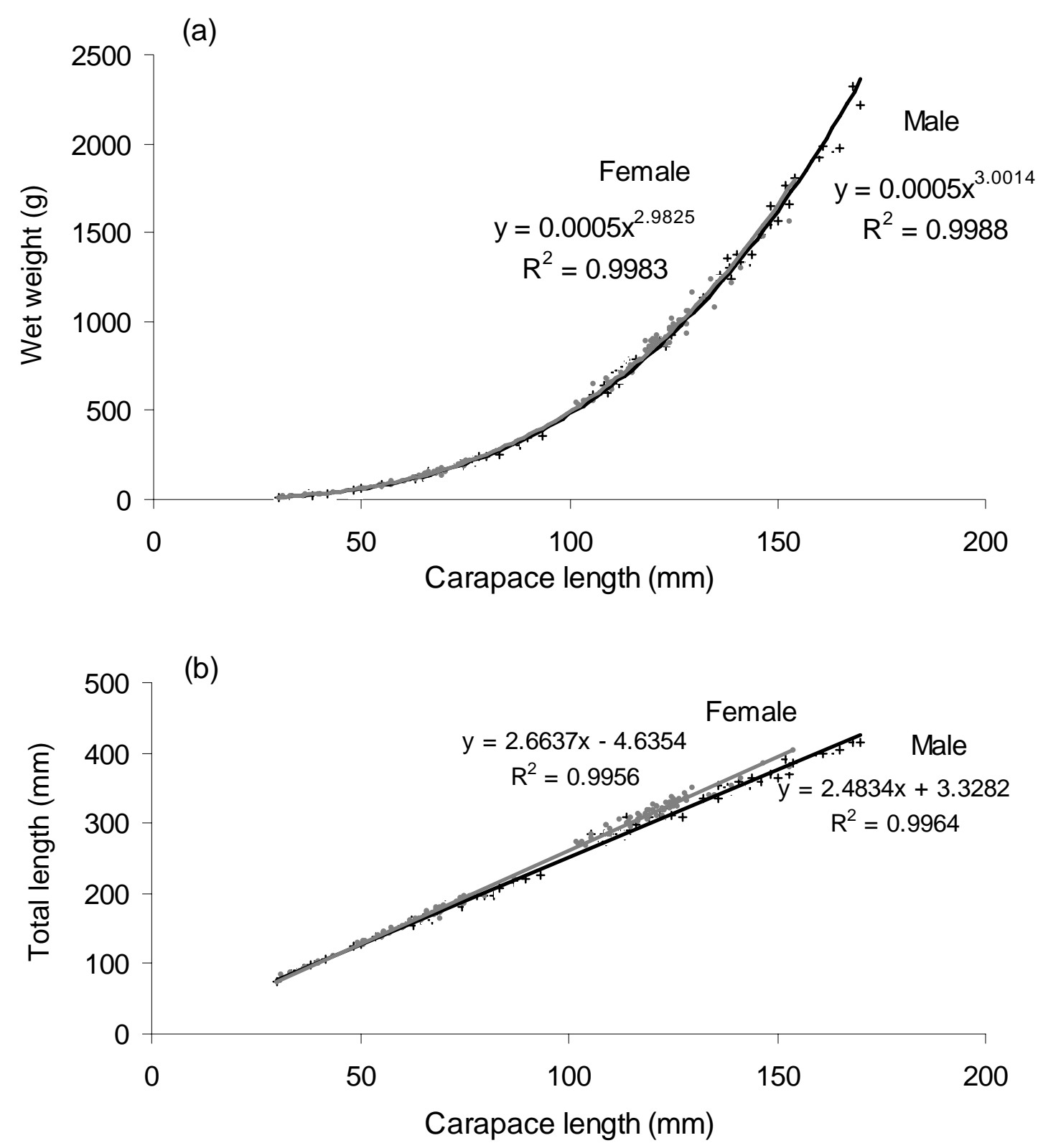

Fig. 1. Relationship between carapace length $(\mathrm{mm})$ of male $(\mathrm{n}=116)$ and female $(\mathrm{n}=122)$ Jasus edwardsii and (a) wet weight (g) or (b) total length (mm). 

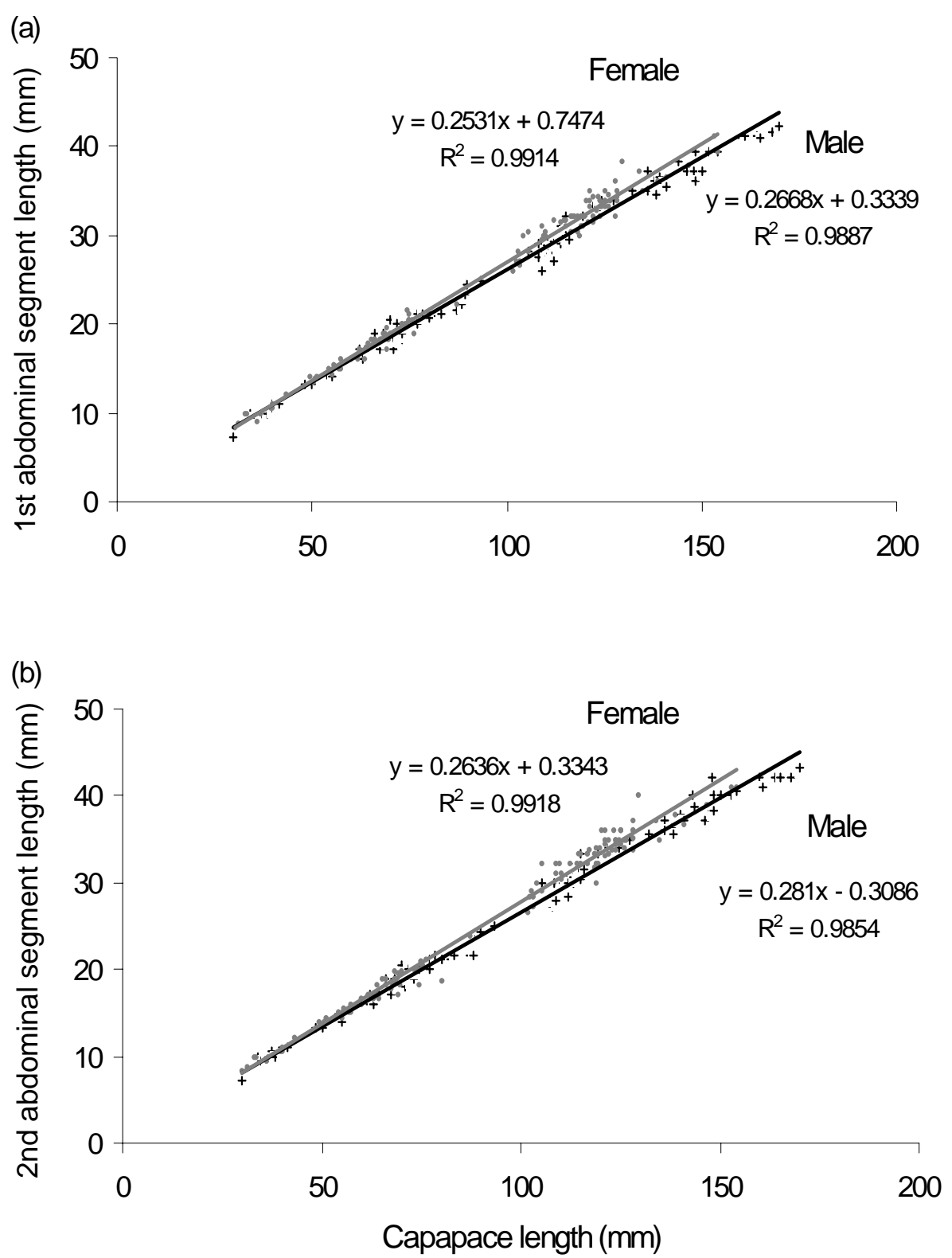

Fig. 2. Relationship between carapace length $(\mathrm{mm})$ of male $(\mathrm{n}=116)$ and female $(\mathrm{n}=122)$ Jasus edwardsii and the length of the (a) $1^{\text {st }}$ or (b) $2^{\text {nd }}$ abdominal segment (mm). 

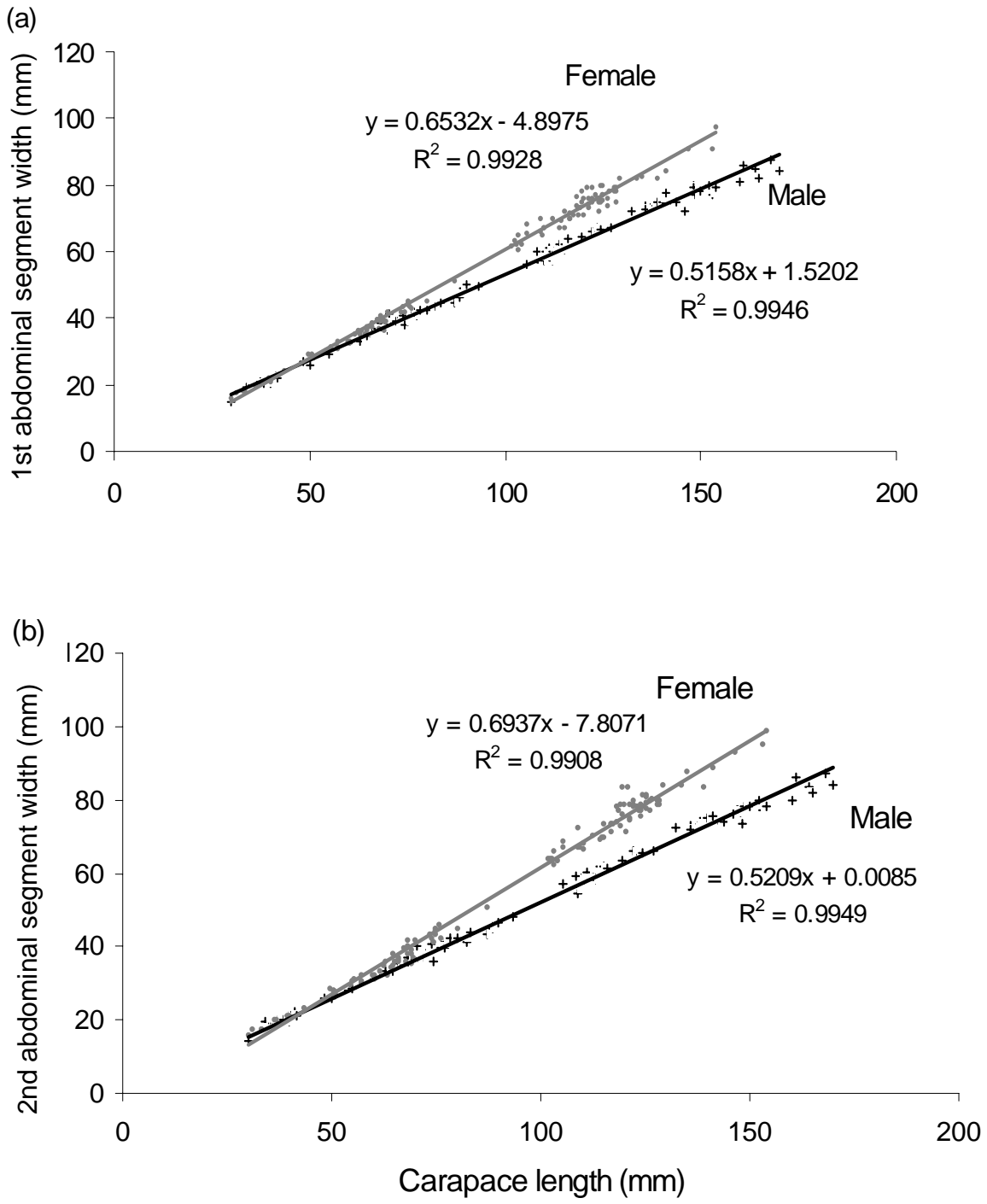

Fig. 3. Relationship between carapace length $(\mathrm{mm})$ of male $(\mathrm{n}=116)$ and female $(\mathrm{n}=122)$ Jasus edwardsii and the width of the (a) $1^{\text {st }}$ or (b) $2^{\text {nd }}$ abdominal segments (mm). 

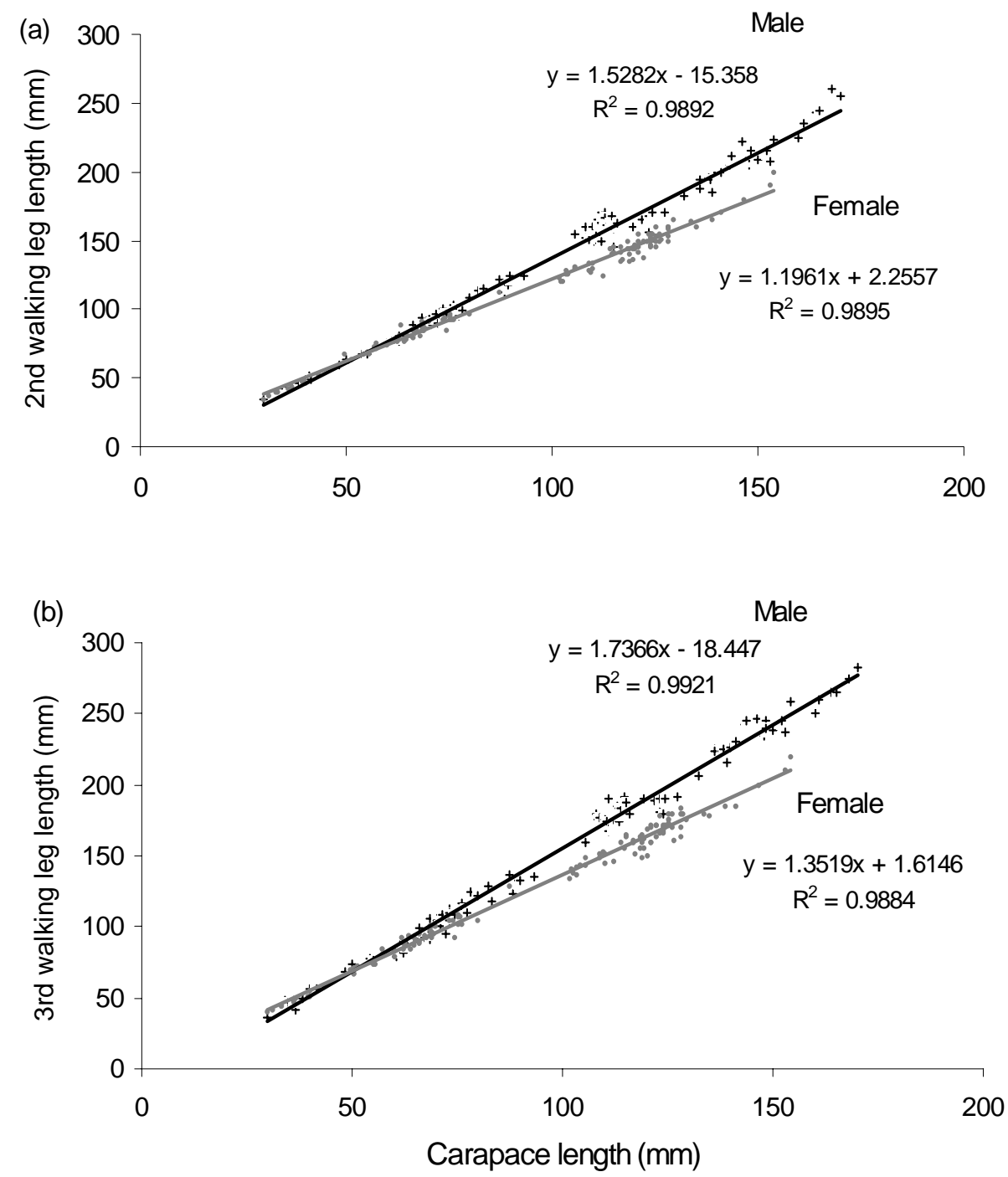

Fig. 4. Relationship between carapace length $(\mathrm{mm})$ of male $(\mathrm{n}=116)$ and female $(\mathrm{n}=122)$ Jasus edwardsii and the length of the (a) $2^{\text {nd }}$ or (b) $3^{\text {rd }}$ walking legs (mm). 


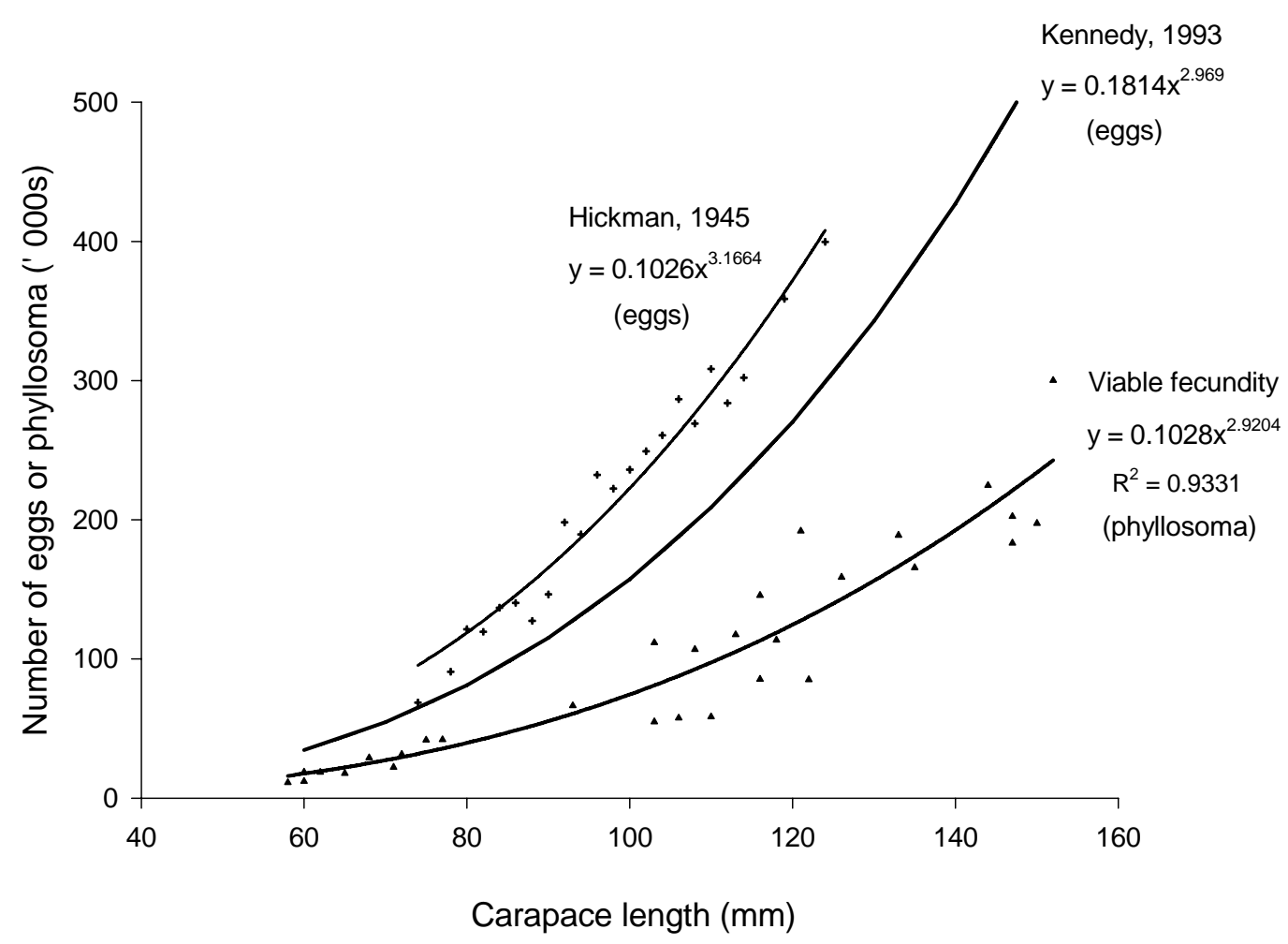

Fig. 5. Relationship between the carapace length (mm) of female Jasus edwardsii and the number of eggs (fecundity) as described by Hickman (1945), Kennedy (1993; unpublished Tasmanian fisheries data) or the number of phyllosoma (viable fecundity) from this study. Viable fecundity was from wild and captive ovigerous females from Bicheno held until hatch $(\mathrm{n}=30)$. 